\title{
Preservice Teachers' Acceptance of Learning Management Software: An Application of the UTAUT2 Model
}

\author{
Arumugam Raman ${ }^{1} \&$ Yahya Don ${ }^{1}$ \\ ${ }^{1}$ School of Education and Modern Languages, Universiti Utara Malaysia, Malaysia \\ Correspondence: Arumugam Raman, School of Education and Modern Languages, UUM, 06010 Sintok, Kedah, \\ Malaysia. Tel: 604-928-4852. E-mail: arumugam@uum.edu.my
}

\author{
Received: May 6, 2013 Accepted: May 24, 2013 Online Published: June 24, 2013 \\ doi:10.5539/ies.v6n7p157 URL: http://dx.doi.org/10.5539/ies.v6n7p157
}

\begin{abstract}
Moodle also known as Learning Management System is freely available to educators. Universiti Utara Malaysia (UUM) encourages students and instructors to utilize the teaching and learning process. Moodle enables lecturer to create sequences and facilitate activities for their students, auto-marked online quizzes and exams, navigation tools, files download, grading, student progress tracking, online calendar, etc. This paper investigated the relationships between the constructs that may influence preservice teachers' acceptance of Learning Zone (Moodle) in their learning process and assessing the influence of variation on performance expectancy, effort expectancy, social influence, facilitating conditions, hedonic motivation, and the habit to the behavioral intention or intention of usage. The Unified Theory of Acceptance and Use of Technology 2 (UTAUT2) is verified and found that the regression model revealed $29.5 \%$ of the variance in student's intentions with facilitating conditions and hedonic expectancy are considerable predictors of the behavioral intention. Based on this, recommendations for prospect research in the application of UTAUT2 are discussed.
\end{abstract}

Keywords: Unified Theory of Acceptance and Use of Technology 2 (UTAUT2), learning zone (Moodle), habit, hedonic motivation, performance expectancy, preservice teacher

\section{Introduction}

Web-based Learning Management Software (LMS) is becoming gradually more important in Malaysian higher education. University Utara Malaysia (UUM) is using Learning zone (Moodle) as an e-learning portal to support teaching and learning process at the university. The platform of university's LMS is Moodle. Moodle is an Open Source Course Management System (CMS), and also called Virtual Learning Environment (VLE). Moodle is free to download and registration is voluntary. The system is installed on the university's web server. It allows lecturers to arrange and facilitate activities for their students. Simple resource activities such as video, sound file, web page, pdf File, spreadsheet, word processor or an activity like auto-marked quizzes. Moodle provides supple activities, providing diverse approaches for learners. There are 11 modules in Learning zone In UUM that a lecturer can use in his class, namely Assignment module, Chats module, Quiz module, Forum module, SCORM (Sharable Content Object Reference Model), Choice module (Poll), Database activity module, Glossary module, Lesson module, Survey module, and Workshop module.

The UUM has three main colleges namely College of Arts and Sciences (CAS-UUM), the College of Business (COB) and the College of Law Government \& International Studies (COLGIS-UUM). The college of CAS -UUM offers undergraduate programme in major arts and science fields and Master's and PhD programmes. One of the programmes offered by the college is Bachelor of Education with a diverse specialization in the fields of moral studies, accounting, business studies, guidance and counseling and information technology. The candidates completed these programmes will be appointed as permanent teachers in various categories of government funded schools.

The objectives of this study are to:

i) Identify the UTAUT2 variables that influence preservice teachers' acceptance of LMS integration in the learning process.

ii) Assess the relationship of UTAUT2 variable that influence LMS usage among preservice teachers. 


\section{Literature Review}

Researchers used different models of technology acceptance to assess preservice teachers' technology acceptance. Venkatesh et al. (2003) designed the Unified Theory of Acceptance and Use of Technology (UTAUT) by incorporating eight IT acceptance models. The earlier UTAUT has four main constructs namely performance expectancy, social influence, effort expectancy and facilitating conditions which influence behavioral intention to use a technology and usage behaviors. Based on UTAUT, performance expectations, effort expectancy, and social influence are critical factors to influence behavioral intention to use a technology, while the behavioral intention and facilitating conditions determine technology use. Furthermore, individual differences such as gender, age and experience are considered as the moderators of the four constructs in the UTAUT model. Recently Venkatesh et al. (2012) made some modifications in the UTAUT model based on their findings from a research conducted in Hong Kong. Venkatesh et al (2012) presented three new constructs to UTAUT model. The first construct is hedonic motivation (intrinsic motivation). The second is price considered as important factor where consumers have to bear the cost associated with the purchase of devices and services but will be excluded from this study due to less relevant (no direct cost imposed). Finally, the third construct is habit. Venkatesh et al. (2012) claimed the suggested additions in UTAUT2 exhibits significant changes in the variance explained in behavioral intention and technology use.

\subsection{Performance Expectancy}

Venkatesh et al. (2003) defined performance expectancy as "the degree to which an individual believes that using the system will help a person to attain gains in job performance". Previous research reports that performance expectancy was a significant forecaster of behavioral intention (Venkatesh et al., 2003).

Hypothesis 1: Performance expectancy will have significant positive influence on behavioral intention.

\subsection{Effort Expectancy}

Effort expectancy is defined as "the degree of ease associated with the use of the system". Previous research supports that latent variables related to effort expectancy that was significant in determining a person's intention to adopt new technology (Zhou et al., 2010; Venkatesh et al., 2012).

Hypothesis 2: Effort expectancy will have significant influence on behavioural intention to use LMS.

\subsection{Social Influence}

Social influence means the extent to which a person perceives how vital others believe he or she should use the technology. Previous research supports that social influence was significant in determining an individual's intention to use new technology (Moore and Benbasat, 1991; Venkatesh et al., 1996; Thompson et al., 1991).

Hypothesis 3: Social influence will have a significant influence on behavioral intention to use LMS.

\subsection{Facilitating Conditions}

Facilitating conditions means the extent of availability of technical support for using the new technology (Venkatesh et al., 2003).

Hypothesis 4: Facilitating conditions will have significant influence on behavioral intention to use LMS.

\subsection{Hedonic Motivation}

Brown and Venkatesh (2005) defined hedonic motivation as an enjoyment or happiness resultant from using a technology and play significant part in determining new technology adoption

Hypothesis 5: Hedonic motivation will have a significant influence on behavioral intention to use LMS.

\subsection{Habit}

Habit is differentiated in two distinct ways. The first habit viewed as prior behaviour (Kim and Malhotra, 2005) and second, habit is where an individual believes the behaviour to be automatic (Lamayem et al., 2007). Venkatesh et al. (2012) modeled habit as having direct and indirect effect through behavioural intention.

Hypothesis 6: Habit will have significant influence on behavioral intention to use LMS. 


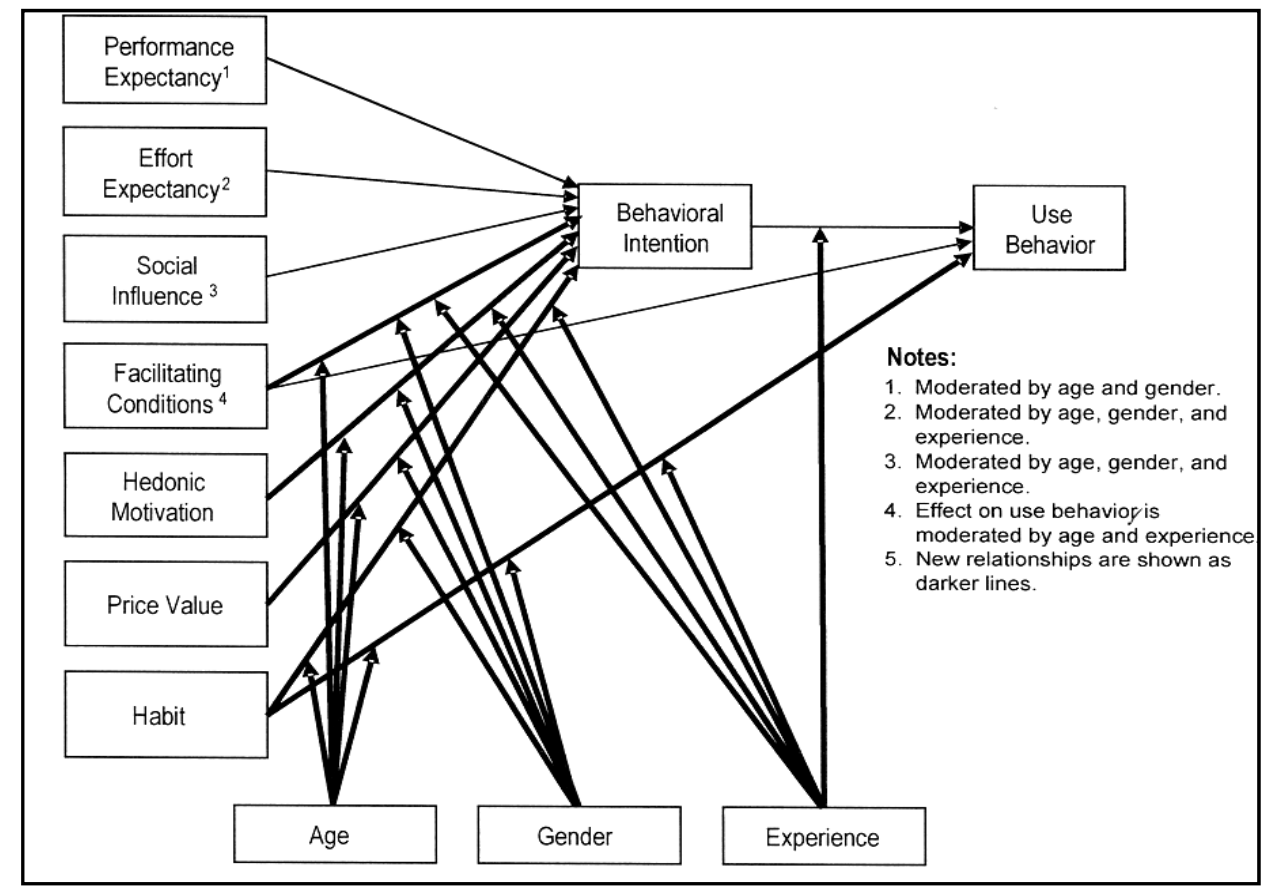

Figure 1. UTAUT2 (Venkatesh et al., 2012)

\subsection{Behavioural Intention}

Based on primary theory for all of the intention models discussed above we expect that behavioral intention would be best forecaster of actual behavior.

Hypothesis 7: Behavioral intention will have a significant influence on use behavior.

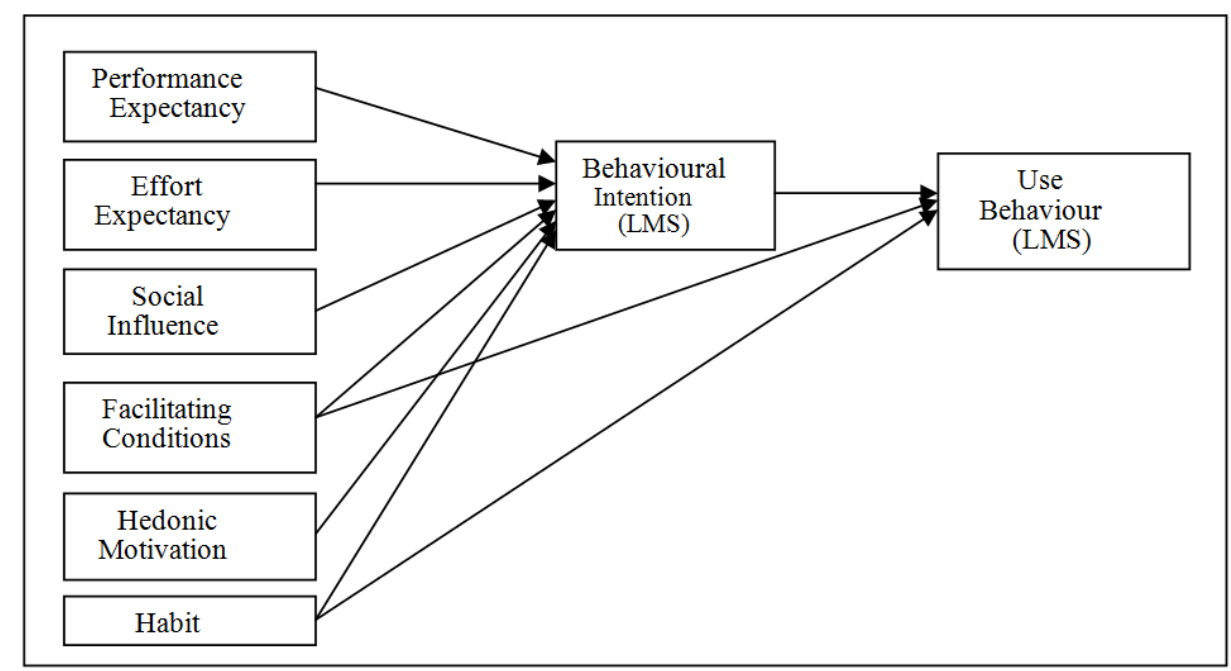

Figure 2. Proposed Research Model

Figure 2, shows UTAUT2 (Venkatesh et al., 2012) that extended three constructs into UTAUT namely, hedonic motivation, price value, and habit. However price value excluded from this study since Moodle if available free

\section{Method}

The research subject is 320 undergraduates' students from school of education and modern languages, University Utara Malaysia. A Google online questionnaire was developed based on the survey recommended by Venkatesh 
et al. (2012). The intake of students for teacher education programs is determined by the MOE. Thus trainees' age range is between 20 to 25 years. The students consist of races including Malays, Chinese, Indians and ethnic groups of Sabah and Sarawak. Table 1 summarised respondents major.

Table 1. Respondents Major

\begin{tabular}{lll}
\hline Major & Frequency & Percent (\%) \\
\hline Education (Business Administration) & 67 & 21 \\
Education (Accounting) & 64 & 20 \\
Education (Information and Technology) & 54 & 17 \\
Education (Moral Education) & 74 & 23 \\
Education (Guidance and Counseling) & 61 & 19 \\
& 320 & 100 \\
\hline
\end{tabular}

\subsection{Data Collection}

Two hundred eighty eight students participated and submitted their answers via online (Google form) which provides 90\% response rate. Data was collected from September 2012 through December 2012.

\subsection{Measures}

The instrument is adopted from Venkatesh et al. (2012). Performance Expectancy (PE) (four items), Effort Expectancy (EE) (four items), Social Influence (SI) (three items), Facilitating Conditions (FC) (four items), Hedonic Motivation (HM) (three items), Habit (H) (four items), Behavioural Intention (BI) three items, and Use Behaviour (U) (Three items). Respondents provided answers to each factor on Likert-type scale (7 point), starting from 1 (strongly disagree) to 7(strongly agree). SmartPLS software is used to compute the loadings, factor loadings, $\mathrm{R}^{2}$, Average Variance Extracted (AVE), and Composite Reliability (CR).

\section{Result}

\subsection{Goodness of Measures}

We used Statistical Package for the Social Science and partial least squares (PLS) to calculate construct validity and reliability. PLS is a prevailing technique of analysis because it is less complex and requires small sample size. First we have to check the validity and reliability which are considered important criteria to test goodness of measures. Anderson-Darling tests confirmed that none of the variables are normally distributed. Thus the use of PLS is suitable for this research since its capability to model latent constructs under non-parametric conditions (Cohen, 1988). Table 2 summarises descriptive statistics for each construct.

Table 2. Descriptive statistics

\begin{tabular}{lccc}
\hline Construct & Total items & Mean & Standard Deviation \\
\hline Performance Expectancy (PE) & 4 & 4.25 & 1.02 \\
Effort Expectancy (EE) & 4 & 5.76 & 1.23 \\
Social Influence (SI) & 3 & 3.78 & 1.21 \\
Facilitating Conditions (FC) & 4 & 5.39 & .952 \\
Hedonic Motivation (HM) & 3 & 4.60 & 1.27 \\
Habit (H) & 3 & 4.65 & 1.22 \\
Behavioural Intention (BI) & 3 & 5.25 & 1.13 \\
Use Behaviour (U) & 3 & 5.25 & 1.11 \\
\hline
\end{tabular}

Most of the items have been validated (Venkatesh et al., 2003). However the survey instruments are re-validated in terms of reliability and construct validity. 


\subsection{Convergent Validity}

Convergent validity ensures that a particular item is designed to measure the construct it is supposed to measure. Fornell and Larcker (1981) proposed average variance extracted (AVE), composite reliability (CR) of each latent variable and reliability of each item in the constructs to assess convergent validity. An AVE of more than 0.50 implies 50\% variance of its items, hence demonstrates adequate convergent validity. The item reliability can be identified by each item's factor loading and cross loadings. The crossloadings from Table 3 show that the values fall in range of 0.7 to 0.9 . These values are more than 0.5, the cutoff point suggested by Hair et al. (2010, and Hair et al. (2006) and deemed to be having significant cross loading. Furthermore, we can observe from the table that each item's loading is higher for its designated construct than for any of the other constructs. The CR of each latent variable (LV) is assessed using Cronbach's $\alpha$. Table 3 revealed that the CR values more than the suggested value 0.7 by Hair et al. (2010). The results show that all eight constructs are valid measures and within the range suggested by Hair

Table 3. Results of measurement model

\begin{tabular}{|c|c|c|c|c|}
\hline Construct & . & Loadings & $\mathbf{A V E}^{\mathbf{a}}$ & $\mathbf{C R}^{\mathrm{b}}$ \\
\hline \multirow[t]{4}{*}{ Performance Expectancy (PE) } & PE1 & 0.758 & 0.639 & 0.879 \\
\hline & PE2 & 0.854 & & \\
\hline & PE3 & 0.747 & & \\
\hline & PE4 & 0.834 & & \\
\hline \multirow[t]{4}{*}{ Effort Expectancy (EE) } & EE1 & 0.725 & 0.705 & 0.905 \\
\hline & EE2 & 0.815 & & \\
\hline & EE3 & 0.892 & & \\
\hline & EE4 & 0.914 & & \\
\hline \multirow[t]{3}{*}{ Social Influence (SI) } & SI1 & 0.902 & 0.739 & 0.894 \\
\hline & SI2 & 0.789 & & \\
\hline & SI3 & 0.884 & & \\
\hline \multirow[t]{4}{*}{ Facilitating Conditions (FC) } & $\mathrm{FC} 1$ & 0.847 & 0.630 & 0.870 \\
\hline & $\mathrm{FC} 2$ & 0.721 & & \\
\hline & FC3 & 0.675 & & \\
\hline & FC4 & 0.909 & & \\
\hline \multirow[t]{3}{*}{ Hedonic Motivation (HM) } & HM1 & 0.851 & 0.652 & 0.849 \\
\hline & HM2 & 0.811 & & \\
\hline & HM3 & 0.758 & & \\
\hline \multirow[t]{3}{*}{ Habit (H) } & H1 & 0.821 & 0.671 & 0.860 \\
\hline & $\mathrm{H} 2$ & 0.804 & & \\
\hline & $\mathrm{H} 3$ & 0.833 & & \\
\hline \multirow[t]{3}{*}{ Behavioural Intention (BI) } & BI1 & 0.875 & 0.758 & 0.904 \\
\hline & BI2 & 0.845 & & \\
\hline & BI3 & 0.891 & & \\
\hline \multirow[t]{3}{*}{ Use Behaviour (U) } & U1 & 0.714 & 0.590 & 0.811 \\
\hline & $\mathrm{U} 2$ & 0.854 & & \\
\hline & U3 & 0.729 & & \\
\hline
\end{tabular}

Note:

a Average Variance Extracted (AVE) is calculated as follows: $\mathrm{AVE}=\frac{\left(\Sigma \lambda_{\mathrm{i}}\right)_{\mathrm{var}} F}{\left(\Sigma \lambda_{\mathrm{i}^{2}}\right) \mathrm{var} \mathrm{F}+\Sigma \Theta_{\mathrm{ii}}}$, 
where, $\lambda_{i}, F, \Theta_{i i}$, are the factor loading, factor variance and unique or error variance respectively

${ }^{\mathrm{b}}$ Composite reliability (CR) calculated as follows: $C R=\rho_{c}=\frac{\left(\left(\Sigma \lambda_{\mathrm{i}}\right)^{2} \operatorname{var} F\right)}{\left(\Sigma \lambda_{\mathrm{i}} 2\right) \operatorname{var} \mathrm{F}+\Sigma \Theta_{\mathrm{ii}}}$

where, $\lambda_{i}, F, \Theta_{i i}$, are the factor loading, factor variance and unique or error variance respectively

\subsection{Discriminant Validity}

Discriminant validity is assessed to compute the degree to which constructs differ. It tests whether the items do not unintentionally measure something else. According to Fornall et al. (1982), discriminant validity exists when an item loads more highly on their own construct it is targeted to measure than items belongings to other constructs. Discriminant validity is achieved if the square of the AVE (BOLD) is higher than correlation between constructs.

Table 4 shows correlation matrix for the constructs. We can see from the table that the diagonal elements (square root of AVE) higher than the off-diagonalelements.

Table 4. Construct correlation matrix

\begin{tabular}{lrrrrrrrrr}
\hline & PE & EE & SI & FC & HM & H & BI & U \\
\hline PE & $\mathbf{0 . 7 9}$ & & & & & & & \\
EE & 0.26 & $\mathbf{0 . 8 4}$ & & & & & & & \\
SI & 0.23 & 0.44 & $\mathbf{0 . 8 6}$ & & & & & & \\
FC & 0.03 & 0.16 & 0.19 & $\mathbf{0 . 7 9}$ & & & & \\
HM & 0.28 & 0.46 & 0.50 & 0.19 & $\mathbf{0 . 8 1}$ & & & \\
H & 0.14 & 0.01 & 0.30 & 0.27 & 0.08 & $\mathbf{0 . 8 2}$ & & \\
BI & 0.05 & 0.26 & 0.49 & 0.38 & 0.19 & 0.22 & $\mathbf{0 . 8 7}$ & \\
U & 0.13 & 0.36 & .017 & 0.04 & 0.25 & 0.23 & 0.05 & $\mathbf{0 . 7 7}$ \\
\hline
\end{tabular}

Note: Diagonal values shows square root of AVE, the off-diagonal shows the correlations between construct

\subsection{Test of the Proposed Model}

Table 5 shows path coefficient. R-squares for each construct (latent variables) represent the amount of variance explained by the model. The results revealed performance expectancy $(\beta=0.256, p<0.01)$, effort expectancy ( $\beta$ $=0.178, \mathrm{p}<0.01)$, social influence $(\beta=0.258, \mathrm{p}<0.01)$, facilitating conditions $(\beta=0.632, \mathrm{p}<0.01)$, and hedonic motivation $(\beta=0.553, \mathrm{p}<0.01)$ have positive effects on behavioural intention (BI). Therefore H1, H2, H3, H4, H5 of this study supported as $\mathrm{R}^{2}$ value 0.295 suggests that $29.5 \%$ variance in LMS use can be explained by extent of behavioural intention and there is positive relationship between behavioural intention (BI) and LMS use (U), $(\beta=0.256), p<0.01$. The researchers found that facilitating conditions is most significant forecaster of the extent of behavioural intention followed by hedonic motivation. The higher the extent of behavioural intention, the higher the usage of LMS. However the habit $(\beta=0.019, \mathrm{p}>0.01)$ does not have positive effects on behavioural intention or LMS use behaviour $(\beta=0.024, \mathrm{p}>0.01)$.

Table 5. Hypothesis testing

\begin{tabular}{lllll}
\hline Hypothesis & Relationship & Coefficient $(\boldsymbol{\beta})$ & $\boldsymbol{t}$ value & Result \\
\hline H1 & PE $\rightarrow$ BI & 0.256 & 2.579 & Supported \\
H2 & EE $\rightarrow$ BI & 0.378 & 2.869 & Supported \\
H3 & SI $\rightarrow$ BI & 0.258 & 3.254 & Supported \\
H4 & FC $\rightarrow$ BI & 0.632 & 2.687 & Supported \\
H5 & HM $\rightarrow$ BI & 0.553 & 2.511 & Supported \\
\hline
\end{tabular}




\begin{tabular}{lllll}
\hline H6 & $\mathrm{H} \rightarrow \mathrm{BI}$ & 0.019 & 0.179 & Not Supported \\
$\mathbf{H 7}$ & $\mathrm{FC} \rightarrow \mathrm{U}$ & 0.791 & 5.263 & Supported \\
$\mathbf{H 8}$ & $\mathrm{H} \rightarrow \mathrm{U}$ & 0.024 & 0.256 & Not Supported \\
$\mathbf{H 9}$ & $\mathrm{BI} \rightarrow \mathrm{U}$ & 0.456 & 5.421 & Supported \\
$\mathbf{H 1 0}$ & $\mathrm{PE} \rightarrow \mathrm{BI} \rightarrow \mathrm{U}$ & & 2.821 & Supported \\
$\mathbf{H 1 1}$ & $\mathrm{EE} \rightarrow \mathrm{BI} \rightarrow \mathrm{U}$ & & 2.652 & Supported \\
$\mathbf{H 1 2}$ & $\mathrm{SI} \rightarrow \mathrm{BI} \rightarrow \mathrm{U}$ & & 3.663 & Supported \\
$\mathbf{H 1 3}$ & $\mathrm{FC} \rightarrow \mathrm{BI} \rightarrow \mathrm{U}$ & & 2.874 & Supported \\
$\mathbf{H 1 4}$ & $\mathrm{HM} \rightarrow \mathrm{BI} \rightarrow \mathrm{U}$ & & 3.114 & Supported \\
$\mathbf{H 1 5}$ & $\mathrm{H} \rightarrow \mathrm{BI} \rightarrow \mathrm{U}$ & & 0.157 & Not Supported \\
\hline
\end{tabular}

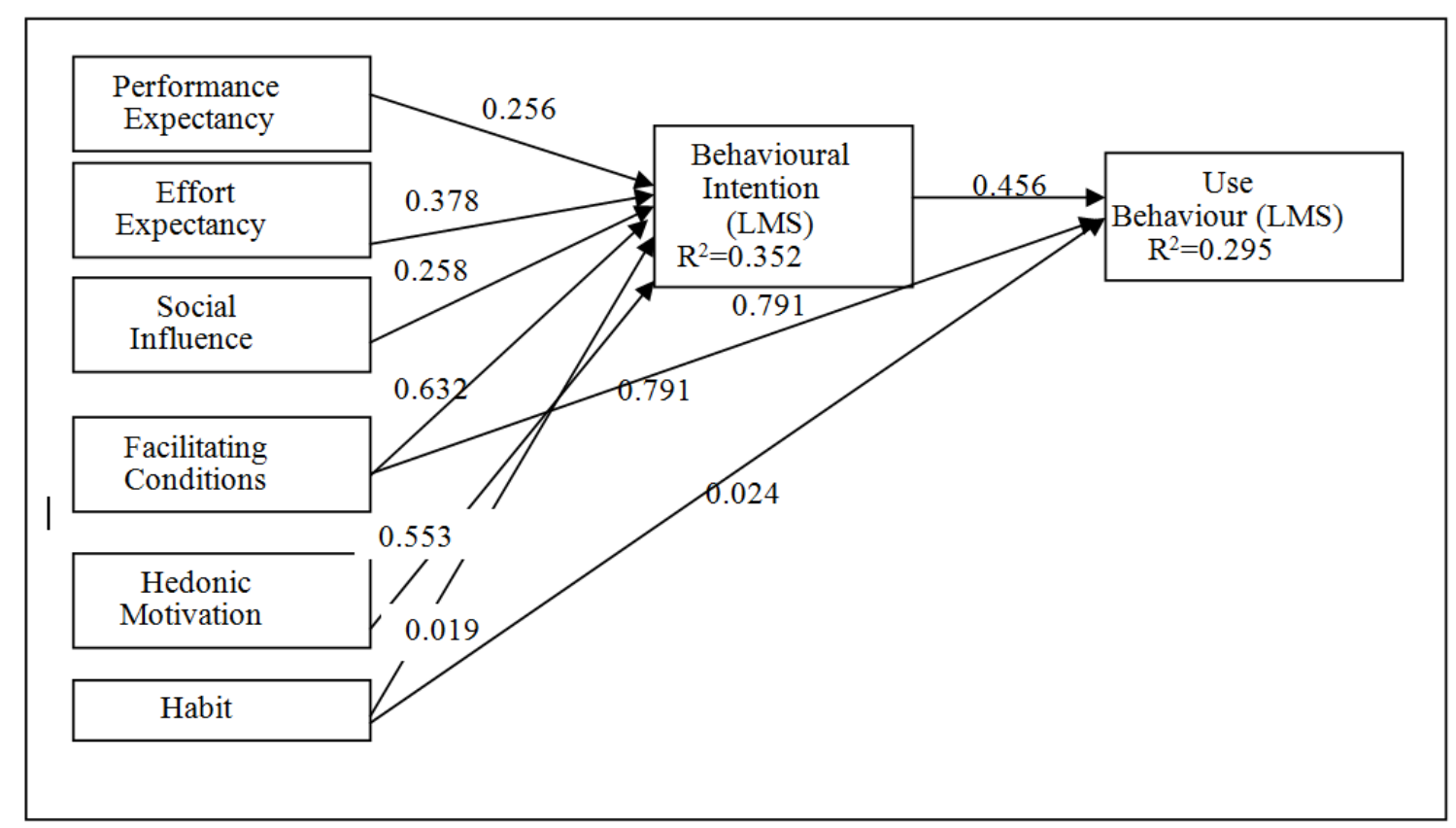

Figure 3. Model Testing Results

\section{Discussion}

The findings of this study supports previous study views of influence of latent variables of performance expectancy, effort expectancy, social influence, facilitating conditions, hedonic motivation and habit on the perceived extent of behavioural intention among the UUM students using partial least square (PLS) in testing hypothesis. Furthermore it examines how this behavioural intention may predict LMS use behaviour.

The findings confirmed the views that performance expectancy and effort expectancy have impact on behavioural intention. This finding is consistent with Venkatesh et al. (2012). Consistent with prior research, social influence appears significant. The new variable introduced by Venkatesh et al. (2012) in UTAUT2 model, hedonic motivation, shows positive influence on behavioural intention use of LMS however habit shows insignificant. This may be the reason that the students use the LMS for academic purposes only. Even though there are many features such as 'chatting' and 'messaging' facilities in 'Moodle' they are not willing to use LMS In UTAUT2 Venkatesh et al., (2012) modeled habit as having both direct effect of use and indirect through behavioural intention. This study is not supporting the claim and further research needed to identify the root of this problem. This model may be less suitable in educational settings and other variables such as security and time of access can be considered to include in this model. 


\section{References}

Brown, S. A., \& Venkatesh, V. (2005). Model of adoption of technology in the household: A baseline model test and extension incorporating household life cycle. MIS Quarterly, 29(4), 399-426.

Cohen, J. (1988). Statistical power analysis for the behavioural sciences (2nd ed.). Hillsdale, NJ. Lawrence Erlbaum Associates.

Fornall, C., Tellis, G. J., \& Zinkhan, G. M. (1982). Validity assessment: A structural equations approach using partial least squares. Proceedings of the American Marketing Association Educators' conference, 48, 405-409. http://dx.doi.org/10.2307/3151312

Fornell, C., \& Larcker, D. F. (1981). Evaluating structural equation models with unobservable variables and measurement error. Journal of Marketing Research, 48, 39-50.

Hair, J. F., Jr, Black, B., Babin, B. J., Anderson, R. E., \& Tatham, R. L. (2006). Multivariate Data analysis (6th ed.). Upper Saddle Rive: NJ, Prentice Hall.

Hair, J. F., William C. B., Babin, B. J., \& Anderson, R. E. (2010). Multivariate Data Analysis. Englewood Cliffs, NJ: Prentice Hall.

Kim, S. S., \& Malhotra, N. K. (2005) A longitudinal model of continued IS use: An integrative view of four mechanisms underlying post-adoption phenomena. Management Science, 51(1), 741-755. http://dx.doi.org/10.1287/mnsc.1040.0326

Lamayem, M., Hirt, S. G., \& Cheung, C. M. K. (2007). How habit limits the predictive power of intentions: The case of IS continuance. MIS Quarterly, 31(4), 705-737.

Moore, G., \& Benbasat, I. (1991). Development of an Instrument to Measure the Perceptions of Adopting an Information Technology Innovation. Information System Research, 2(3), 192-222. http://dx.doi.org/10.1287/isre.2.3.192

Thompson, R. L., Higgins, C. A., \& Howell, J. M. (1991). Personal computing: Toward a conceptual model of utilization. MIS Quarterly, 15(1), 125-143. http://dx.doi.org/10.2307/249443

Venkatesh, V., Morris, M. G., Davis, G. B., \& Davis, F. D. (2003). User acceptance of information technology: Toward a unified view. MIS Quarterly, 27(3), 425-478.

Venkatesh, V. Y. L. Thong, J., \& Xu, X. (2012). Consumer acceptance and use of information Technology: Extending the unified theory of acceptance and use of technology. MIS Quarterly, 36(1), 157-178.

Zhou, T., Lu, Y. B., \& Wang, B. (2010). Integrating TTF and UTAUT to explain mobile banking user adoption. Computer in Human Behaviour, 26(4), 760-767. http://dx.doi.org/10.1016/j.chb.2010.01.013

\section{Copyrights}

Copyright for this article is retained by the author(s), with first publication rights granted to the journal.

This is an open-access article distributed under the terms and conditions of the Creative Commons Attribution license (http://creativecommons.org/licenses/by/3.0/). 